\title{
MAP7 Regulates Axon Collateral Branch Development in Dorsal Root Ganglion Neurons
}

\author{
(D) Stephen R. Tymanskyj, Benjamin Yang, Aditi Falnikar, Angelo C. Lepore, and $\oplus^{\circ}$ Le Ma \\ Department of Neuroscience, Vickie and Jack Farber Institute for Neuroscience, Sydney Kimmel Medical College, Thomas Jefferson University, \\ Philadelphia, Pennsylvania 19107
}

Collateral branches from axons are key components of functional neural circuits that allow neurons to connect with multiple synaptic targets. Like axon growth and guidance, formation of collateral branches depends on the regulation of microtubules, but how such regulation is coordinated to ensure proper circuit development is not known. Based on microarray analysis, we have identified a role for microtubule-associated protein 7 (MAP7) during collateral branch development of dorsal root ganglion (DRG) sensory neurons. We show that MAP7 is expressed at the onset of collateral branch formation. Perturbation of its expression by overexpression or shRNA knockdown alters axon branching in cultured DRG neurons. Localization and time-lapse imaging analysis reveals that MAP7 is enriched at branch points and colocalizes with stable microtubules, but enters the new branch with a delay, suggesting a role in branch maturation. We have also investigated a spontaneous mutant mouse that expresses a truncated MAP7 and found a gain-of-function phenotype both in vitro and in vivo. Further domain analysis suggests that the amino half of MAP7 is responsible for branch formation, suggesting a mechanism that is independent of its known interaction with kinesin. Moreover, this mouse exhibits increased pain sensitivity, a phenotype that is consistent with increased collateral branch formation. Therefore, our study not only uncovers the first neuronal function of MAP7, but also demonstrates the importance of proper microtubule regulation in neural circuit development. Furthermore, our data provide new insights into microtubule regulation during axonal morphogenesis and may shed light on MAP7 function in neurological disorders.

Key words: axon; collateral branch; DRG; MAP7; microtubule; sensory neuron

Significance Statement

Neurons communicate with multiple targets by forming axonal branches. In search of intrinsic factors that control collateral branch development, we identified a role for microtubule-associated protein 7 (MAP7) in dorsal root ganglion sensory neurons. We show that MAP7 expression is developmentally regulated and perturbation of this expression alters branch formation. Cell biological analysis indicates that MAP7 promotes branch maturation. Analysis of a spontaneous mouse mutant suggests a molecular mechanism for branch regulation and the potential influence of collateral branches on pain sensitivity. Our studies thus establish the first neuronal function of MAP7 and demonstrate its role in branch morphogenesis and neural circuit function. These findings may help in our understanding of the contribution of MAP7 to neurological disorders and nerve regeneration.

\section{Introduction}

Establishment of neural networks is generated from trillions of synaptic connections from billions of neurons. The increased

\footnotetext{
Received Oct. 12, 2016; revised Dec. 27, 2016; accepted Jan. 4, 2017.

Author contributions: S.R.T. and L.M. designed research; S.R.T., B.Y., and A.F. performed research; S.R.T. and B.Y. contributed unpublished reagents/analytic tools; S.R.T., A.F., A.C.L. and L.M. analyzed data; S.R.T. and L.M. wrote the paper.

This work was supported by the National Institutes of Health (Grant NS062047 to L.M.) We thank Zhen Zhao, Zheng Wang, and Joe Hacia for microarray analysis; Zhen Zhao, Caihong Xia, and Muye Zhu for preliminary studies; Zongxiu Zhang for in situ analysis; Matthew Dalva and members of the Ma laboratory for helpful discussion; and Erik Dent and Peter Baas for comments on an early version of the manuscript.

The authors declare no competing financial interests.

Correspondence should be addressed to Le Ma, Ph.D, Department of Neuroscience, Vickie and Jack Farber Institute for Neuroscience, Sydney Kimmel Medical College, Thomas Jefferson University, 900 Walnut Street, JHN 406, Philadelphia, PA 19107. E-mail: le.ma@jefferson.edu.
}

number of synapses is partly a result of the neuron's ability to form multiple axonal branches, which allow it to synapse with multiple dendritic targets (Gibson and Ma, 2011; Kalil and Dent, 2014). One example is the collateral branches formed from the dorsal root ganglion (DRG) sensory neurons. These evolutionary conserved structures allow DRG neurons to make reflex connections with motor neurons either directly (monosynaptically) or indirectly (polysynaptically) (Arber et al., 2000; Patel et al., 2003; Gibson and Ma, 2011). Although they have been known for more than a century (Cajal, 1995), the precise molecular mechanism 
regulating DRG collateral branch formation during development is not fully understood.

Recent studies have suggested that formation of collateral branches is regulated by the interplay between extracellular cues and intrinsic programs, which eventually leads to the reorganization of the cytoskeleton (Gallo, 2011; Bilimoria and Bonni, 2013; Kalil and Dent, 2014). Nascent branches usually start with filopodial extension, which is initiated by local actin assembly along the axons (Gallo, 2011; Kalil and Dent, 2014; Winkle et al., 2016). Filopodia are highly dynamic and do not develop into mature branches until the invasion of microtubules (Gallo and Letourneau, 1999; Dent and Kalil, 2001; Gallo, 2011; Kalil and Dent, 2014). Although microtubule transport, polymerization, and reorganization are thought to be important for branch formation, how microtubules are regulated at different steps of branch development is not completely understood (Ketschek et al., 2015).

Several classes of microtubule-associated proteins (MAPs) have been implicated in branch formation (Lewis et al., 2013; Kapitein and Hoogenraad, 2015). For example, spastin and katanin have been suggested to promote branching by severing existing microtubules to generate new plus ends or fragments (Qiang et al., 2010). However, many known MAPs seem to negatively regulate branching but via different mechanisms: tau protects microtubules from severing (Qiang et al., 2006), MAP1B influences tubulin acetylation and subsequent cargo transport (Bouquet et al., 2004; Tymanskyj et al., 2012), and Kif2A destabilizes microtubules (Homma et al., 2003). Although past studies have provided useful insights into MAP functions in branching, it is not clear how these MAPs regulate collateral branches during development.

Our investigation of the developmental mechanism of DRG sensory neurons led to the identification of the less well studied MAP7 in branch regulation. MAP7 (also known as ensconsin or E-MAP-115) was originally identified based on its association with microtubules (Masson and Kreis, 1993; Bulinski and Bossler, 1994) and later characterized in non-neuronal cells (Bulinski et al., 1999; Faire et al., 1999). The function of MAP7 has mainly been studied in Drosophila, in which it interacts with kinesin-1 and regulates cell polarity in oocytes, nuclear position in muscle cells, organelle transport in S2 cells, and spindle length during neural stem cell division (Sung et al., 2008; Metzger et al., 2012; Barlan et al., 2013; Gallaud et al., 2014; Ketschek et al., 2015). In mammals, the only known MAP7 function is linked to spermatogenesis and histocompatibility (Komada et al., 2000; Magnan et al., 2009). Despite its expression in the nervous system (FabreJonca et al., 1998; Komada et al., 2000) and the recent finding of MAP7 association with autism and schizophrenia (Torri et al., 2010; Venkatasubramanian, 2015; Rouillard et al., 2016), the function of MAP7 in neurons has not been investigated.

In this study, we first demonstrate the role of MAP7 in the developmental regulation of collateral branches of DRG sensory axons. We also show that MAP7 binds to microtubules at branch sites to promote branch maturation. By studying a spontaneous mouse mutant, we map this function to the $\mathrm{N}$-terminal half of MAP7. Finally, we demonstrate the potential connection between branch development and reflex functions. Therefore, our study uncovers a novel neuronal function for MAP7 in collateral branch morphogenesis and demonstrates the importance of proper microtubule regulation in neural circuit development.

\section{Materials and Methods}

DNA constructs and transgenic animals. MAP7 constructs based on the mouse sequence (BC052637) were created by PCR and confirmed by sequencing. C-terminal tagged fusion proteins were created by subcloning the PCR products into the EGFP-N3 vector. When noted, a pCAGGS vector expressing mCherry was cotransfected to visualize neuronal morphology. The shRNA construct against the rat MAP7 sequence (CCTC GTCTGCAACTTTGCTAA) is based on the design of the RNAi consortium (Moffat et al., 2006) and was subcloned behind a U6 promoter in a shRNA expression vector that coexpresses mCherry. The $M a p 7^{\text {mshi }}$ mouse line was obtained from The Jackson Laboratory (RRID: MGI:5608791) and maintained in accordance with National Institutes of Health regulations. Embryos were obtained from timed pregnant mice or Sprague Dawley rats (Charles River Laboratories), with vaginal plug dates designated as embryonic day 0.5 (E0.5) for mouse and E0 for rat.

Expression analysis by microarray and in situ hybridization. Microarray analysis was done with pooled mouse DRG samples taken from E12.5 or E15.5 embryos in triplicate using the Affymetrix Mouse Genome 4302.0 Array. For in situ hybridization, cryosections $(16-20 \mu \mathrm{m})$ were processed following a standard procedure (Zhao et al., 2009) using DIGlabeled riboprobes. The Map7-specific RNA probes were subcloned into the pCRII-TOPO vector (Invitrogen) with the following primers: $\mathrm{N}$-terminal probe $(250 \mathrm{bp}$ ): forward, ATCCCCCACCTGTGCTACG; reverse, CTTGTCCTCCTCCAGCCTCTG; C-terminal probe (543 bp), forward: ACAGCAATCAGAAGTGACCACAGAGAG; reverse, TGTCT GCACACCATCCACCT.

Primary DRG neuron culture. Primary rat DRG neuronal cultures were performed as described previously (Zhao et al., 2009). Briefly, DRGs were dissected out from E14 or E17 rat embryos, washed once in HBSS, and incubated at $37^{\circ} \mathrm{C}$ with $0.25 \%$ trypsin for $10-15$ min. Trypsin-treated DRGs were resuspended in L15 medium plus 10\% horse serum and then mechanically triturated with a fire-polished glass pipette. Dissociated rat DRG neurons $\left(\sim 7.5 \times 10^{5}\right.$ cells $)$ were transfected with various constructs by nucleofection (Lonza) using reagent $\mathrm{P} 3$ and the CU-133 program and then cultured at $\sim 30,000$ cells on $18 \mathrm{~mm}$ glass coverslips coated with $10 \mu \mathrm{g} / \mathrm{ml}$ poly-D-lysine and $10 \mu \mathrm{g} / \mathrm{ml} \mathrm{laminin} \mathrm{in} \mathrm{F12} \mathrm{medium} \mathrm{(with}$ the $\mathrm{N} 3$ supplement, $40 \mathrm{~mm}$ glucose, and $25 \mathrm{ng} / \mathrm{ml} \mathrm{NGF}$ ). Cells were fixed in $4 \%$ PFA after $24 \mathrm{~h}$ for immunocytochemical analysis.

$M a p 7^{\text {mshi }}$ neurons were first collected from E15.5 mouse embryos. After PCR genotyping, DRGs with the same genotypes were then pooled and processed for culture as described above. Cultures were grown for $24 \mathrm{~h}$ before fixation with $4 \%$ PFA.

Immunocytochemistry and imaging. MAP7 in DRG neurons was visualized directly by the fluorescence of the EGFP tag. Neuronal morphology was visualized by antibody staining for mCherry (1:2000, Rockland catalog \#600-401-379, RRID:AB_2209751), which was expressed from the cotransfected pCAGGS-mCherry vector or the shRNA vector. Other structures were visualized based on the following primary antibodies: $\alpha$-tubulin (1:5000, Abcam catalog \#ab18251, RRID:AB_2210057), C-terminal MAP7 (1:1000, GeneTex catalog \#GTX120907, RRID:AB_11170884), acetylated tubulin (1:1000, Sigma-Aldrich catalog \#T6793, RRID:AB_477585), or neurofilament (1:1000, V.M. Lee, University of Pennsylvania catalog \#RMO 270, RRID:AB_2315286). For antibody labeling, PFA-fixed neurons were blocked in PBS plus 5\% goat serum and $0.1 \%$ Triton (PGT) for $1 \mathrm{~h}$ and then incubated with primary antibodies diluted in PGT for at least $1 \mathrm{~h}$ at room temperature or overnight at $4^{\circ} \mathrm{C}$. After washing, they were incubated with $\mathrm{Cy} 3$ and/or Cy5-labeled secondary antibodies (Jackson ImmunoResearch) diluted in PGT for $1 \mathrm{~h}$ at room temperature. Digital images were taken on a Leica SP8 point scanning confocal system or a Yokogawa spinning disk confocal system using 488, 560, or $680 \mathrm{~nm}$ laser excitation with a $20 \times$ or $40 \times$ objective. Images are shown as $2 \mathrm{D}$ projections unless otherwise stated.

Branch analysis. From the digital confocal images, the following parameters were analyzed in ImageJ (RRID:SCR_003070): number of primary axons per neuron, main axon length, and number of branching points. Axons were divided into two regions based on the length of the axon. Branches emerging form the distal $10 \%$ of the axon were defined as terminal branches and those emerging from the other $90 \%$ of the axon were termed interstitial branches and considered collateral branches. The longest axon of each neuron was measured from the cell body to the growth cone. The numbers of primary axons were counted as any processes longer than $20 \mu \mathrm{m}$ extending from the cell body. Branches longer 
than $10 \mu \mathrm{m}$ were traced and counted. Each condition was repeated $>3 \times$, with $>20$ neurons analyzed. For acetylated tubulin analysis, line scans were taken along the branch and the fluorescent intensity of acetylated or $\alpha$-tubulin was measured and used to calculate the intensity ratio.

Live-cell imaging. E14 rat neurons were dissociated and transfected as above and then cultured in laminin-coated glass-bottom dishes (MatTek). The dish was mounted into a heated and humidified chamber (OkoLab) equilibrated to $37^{\circ} \mathrm{C}$ with $5 \% \mathrm{CO}_{2}$ on an inverted microscope (Axiovert 200; Zeiss). Both bright-field and fluorescent images were acquired using a spinning disk confocal system (Yokogawa W1) with an sCMOS camera (Zyla; Andor) or an EMCCD camera (Cascade 512; Photometrics). For branch analysis, images were taken using a $20 \times$ objective every $5 \mathrm{~min}$ for $18 \mathrm{~h}$. For filopodia analysis, images were taken using a $63 \times$ objective every $2 \mathrm{~min}$ for $30 \mathrm{~min}$. Image contrast was auto-adjusted in ImageJ using $\min / \max$ values. Some of the bright-field images in Fig. $5 A$ were contrast enhanced in ImageJ using $0.1 \%$ saturated pixels and stack histogram.

DiI analysis of collateral formation in spinal cords. For single-cell DiI labeling, E15.5 mouse embryos were fixed briefly with 4\% PFA in PBS. A small amount of DiI was injected into the DRG by iontophoresis from a micropipette with a $1 \mu \mathrm{m}$ opening (Ma and Tessier-Lavigne, 2007). After overnight incubation at $37^{\circ} \mathrm{C}$, spinal cords were dissected out and imaged on the Leica SP8 confocal system using a $10 \times$ objective and $560 \mathrm{~nm}$ laser excitation. Only clearly distinguishable single-labeled axons were used for analysis.

Hargreaves analgesia test. The Hargreaves apparatus (UgoBasile) was used to assess forepaw withdrawal latency of 6-month-old males in response to application of a thermal stimulus to the forepaw plantar surface (Hargreaves et al., 1988; Falnikar et al., 2016). Three trials were conducted for each forepaw during each testing session, with an intertrial interval of $120 \mathrm{~s}$. The tester was blinded to the group identity of all animals.

Neurofilament whole-mount staining. Forelimbs from E15.5 embryos were fixed in PFA overnight and subsequently dehydrated with methanol and bleached with $\mathrm{H}_{2} \mathrm{O}_{2}$ and rehydrated. Limbs were blocked in 5\% goat serum plus $20 \%$ DMSO in PBS for $>2 \mathrm{~h}$ and then incubated with primary antibodies against neurofilament (2H3, 1:200; DSHB catalog \#2H3, RRID:AB_531793) for $3 \mathrm{~d}$. Limbs were washed with 20\% DMSO in PBS for $6 \mathrm{~h}$. After incubation with Cy2-labeled secondary antibodies overnight, limb tissues were washed for $6 \mathrm{~h}$ again. Before imaging, the tissues were cleared in CUBIC1 solution (Susaki et al., 2014) for $>2$ h. Images were taken on the spinning disk confocal system using a $10 \times$ objective.

Statistical analysis. All measurements are presented as mean \pm SEM. Statistical analysis was performed in GraphPad Prism 5.0 software (RRID:SCR_002798). When comparing two different experimental conditions, the Kolmogorov-Smirnov test was done first. If the data were normally distributed, then the significance was determined with unpaired two-tailed independent $t$ tests; if not, then the Mann-Whitney test was performed (see Figs. $3 C, 5 D, 6,8 J, 9 D) . p<0.05$ was considered significant and represented by asterisks in the figure legends. Fisher's exact test was also performed for the category comparison shown in Figures $6 D$ and $9 D$.

\section{Results}

\section{MAP7 is expressed in DRG neurons during collateral} branch formation

The central projections of DRG neurons first bifurcate at the dorsal spinal cord and then sprout collaterals that invade the gray matter, forming reflex circuits involved in nociception and proprioception (Gibson and Ma, 2011). During embryonic development, these collaterals do not form immediately upon reaching the dorsal spinal cord; the first collaterals emerge only after a waiting period of 2-3 d (Mirnics and Koerber, 1995; Ozaki and Snider, 1997). This developmental switch can be recapitulated in culture (Wang et al., 1999). DRG neurons isolated before collateral branch growth from rat E14 (rE14) or mouse E12.5 (mE12.5) embryos produced simple axonal morphologies consisting of one or two unbranched axons (Fig. 1A). In contrast, neurons isolated from older animals (rat E17 (rE17) or mouse E15.5 (mE15.5)), in which collaterals had already developed, produced a more elaborate branching phenotype (Fig. $1 B$ ).

To identify the molecular mechanism responsible for this development switch, we performed microarray analysis of E12.5 and E15.5 mouse DRGs. Because several MAPs have been shown to be developmentally regulated in neurons (Tucker, 1990), we compared the expression of the MAPs that were present in the microarray library. Among all available probes, we detected the largest difference for MAP7, with an 2.7-fold increase between mE12.5 and mE15.5 (Fig. 1C). Most other MAPs showed modest changes, with $\leq 1.6$ increases or decreases in mE15.5 DRGs. For example, tau was increased by 1.6-fold, whereas MAP2 was decreased by 1.5 -fold. The only other MAP that showed $>2$-fold increase was MAP1A, which is based on a single probe.

Because of its largest increase in mE15.5 over mE12.5 DRGs, we then performed in situ analysis (Fig. $1 D-I$ ) to examine MAP7 mRNA expression in spinal cord sections using an N-terminal probe. The analysis confirms this difference and further revealed the expression dynamics. At mE12.5, MAP7 expression was not detected in DRGs (Fig. $1 F$ ); at mE13.5, it started to appear in a subset of DRG neurons (Fig. $1 D, G$ ) and, by mE14.5, all visible neurons inside DRGs expressed MAP7 (Fig. 1H). This expression peaks at $\mathrm{mE15.5}$, a time when neurons are forming collaterals in vivo (Fig. $1 E, I$ ), and continues to be expressed in adult DRGs (Allen Brain Atlas). This temporal expression pattern suggests that MAP7 likely contributes to the developmental switch that promotes collateral branch development.

\section{Precocious expression of MAP7 is sufficient to promote collateral branch formation in cultured E14 rat DRG neurons} To establish the developmental role of MAP7, we took advantage of rE14 DRG neurons, which, like mE12.5 neurons, lack endogenous MAP7 expression (data not shown) and do not produce many branches (Fig. 1A). We overexpressed EGFP-tagged MAP7 in these neurons, along with mCherry to visualize branch morphology. Like the untransfected neurons shown above (Fig. 1A), EGFP-expressing control neurons grew only one or two axons with few branches (Fig. $2 A$ ). In contrast, overexpression of MAP7 (Fig. $2 B$ ) led to a profound increase in the branch number (Fig. $2 C$ ) without affecting the axon number per cell (Fig. 2E). By counting the total number of tips extending from the main axon, we found that the number of branches per cell increased by 3.1fold (Fig. 2C). The main axon was also shortened by $\sim 39 \%$ (Fig. 2D); therefore, the branch density was increased by 4.5 -fold.

To understand whether MAP7 affects collateral branches, we further analyzed the branches formed by tracing where the branches (defined as those longer than $10 \mu \mathrm{m}$ ) originated from on the main axonal shaft and divided them into two working groups, interstitial and terminal branches. Interstitial branches were defined as those extending from the main shaft and omitting the distal $10 \%$ of the total length from the growth cone, likely representing collateral branches. In contrast, terminal branches were defined operationally as those extending from the distal end of axons and occupying the last $10 \%$ of the axon. As shown above, expression of MAP7 showed a 7.5-fold increase in interstitial (or collateral) branches compared with EGFP expression (Fig. 2B, arrows), whereas the number of terminal branches remained the same (Fig. 2C). Therefore, precocious expression of MAP7 could stimulate interstitial branch formation in rE14 DRG neurons, consistent with its potential role in collateral formation. 


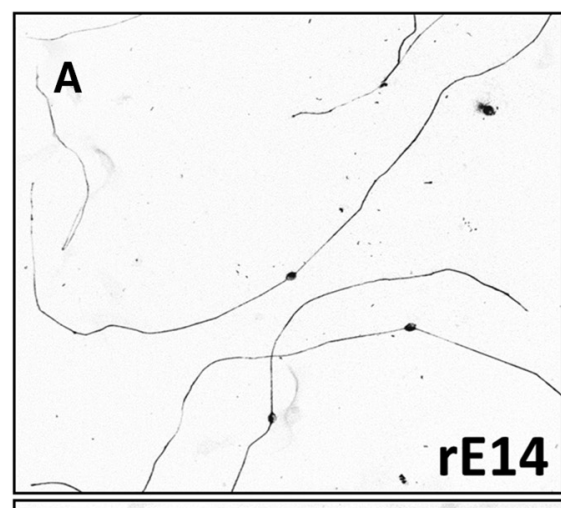

C
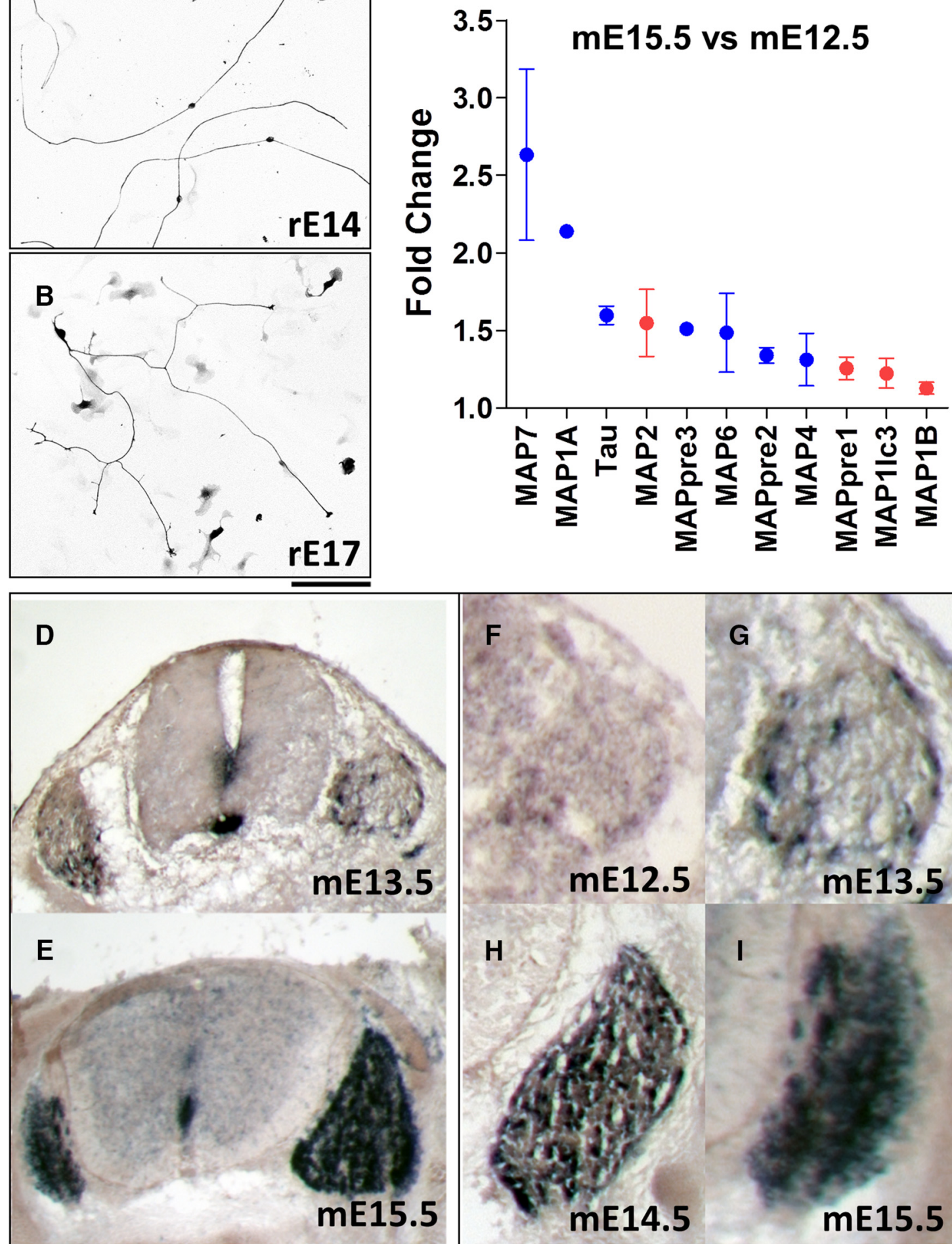

Figure 1. MAP7 expression is upregulated in DRGs at the time of collateral branch formation. $\boldsymbol{A}, \boldsymbol{B}$, Inverted fluorescent images of dissociated DRG neurons that were isolated from rE14 ( $\boldsymbol{A}$ ) or rE17 $(\boldsymbol{B})$ embryos and grown overnight on laminin-coated coverslips and then immunostained for neurofilament. C, Expression differences (fold change, mE15.5 vs mE12.5) of all known MAPs present in the microarray analysis of mouse DRGs. Blue markers indicate an increase in expression at $\mathrm{mE} 15.5$ and red markers indicate a decrease. D-I, RNA in situ hybridization analysis of MAP7 transcripts using the N-terminal probe are shown in the transverse sections of developing mouse embryos between mE12.5 and mE15.5. Low-magnification images are shown for both DRG and spinal cord ( $\boldsymbol{D}$, E) and high-magnification images are shown for individual DRGs $(\boldsymbol{F}-\boldsymbol{I})$. Scale bars, $100 \mu \mathrm{m}$. 

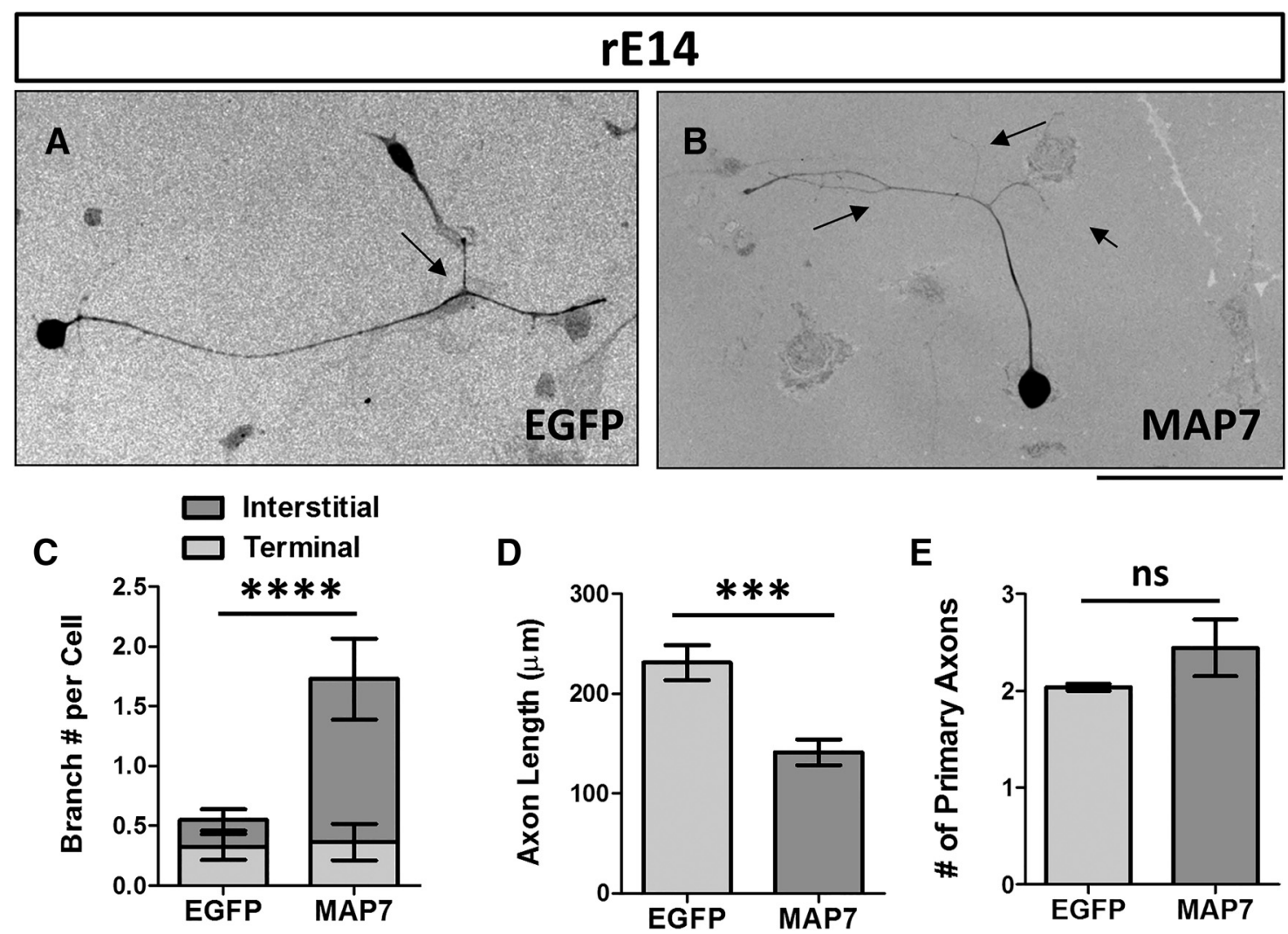

Figure 2. Overexpression of MAP7 increases branch formation in cultured rat DRG neurons. $\boldsymbol{A}, \boldsymbol{B}$, Inverted mCherry fluorescent images of dissociated rE14 DRG neurons expressing EGFP ( $\boldsymbol{A}$ ) or MAP7-EGFP $(\boldsymbol{B})$. Neurons were cotransfected with pCAGGS-mCherry for visualization and cultured on laminin substrates for $24 \mathrm{~h}$ before staining. Arrows point to interstitial branches. $\boldsymbol{C}-\boldsymbol{E}$, Quantification of the number (\#) of branches $(\boldsymbol{C})$ as measured by counting the total number of tips per neuron in rE14 DRG neurons shown in $\boldsymbol{A}$ and $\boldsymbol{B}$ (EGFP: $0.55 \pm 0.13$; MAP7: 1.7 $\pm 0.4, p<$ 0.0001 ), length of main axons $(\boldsymbol{D})$, and number (\#) of primary axons $(\boldsymbol{E})$. Branches were further divided into two groups: terminal branches arising from the distal $10 \%$ part of the axon (EGFP: $0.32 \pm$ 0.11 ; MAP7: $0.36 \pm 0.15, p>0.05$ ) and interstitial branches from the remaining 90\% of the axon (EGFP:0.23 \pm 0.09 ; MAP7: $1.4 \pm 0.3)(C)$. $\left(n=52\right.$ for EGFP and 32 for MAP7-EGFP). ${ }^{* * *} p<0.001$; ${ }^{* * * *} p<0.0001$; ns: not significant from $t$ test. Scale bar, $100 \mu \mathrm{m}$.

\section{Knockdown of MAP7 reduces collateral branch formation and axonal length in cultured E17 rat DRG neurons}

We next used shRNA knockdown to test the requirement of MAP7 for branch formation in rE17 DRG neurons, which, like mE15.5 neurons, express MAP7 (data not shown) and produce many branches in culture (Figs. 1B, 2E). We first generated an shRNA construct and validated its efficiency in knocking down MAP7 overexpression in COS cells. As shown by Western analysis, coexpression with MAP7 and an shRNA control had no effect on MAP7 expression, but cotransfection with a MAP7 specific shRNA led to a complete elimination of MAP7 protein production $24 \mathrm{~h}$ after transfection (Fig. $3 A$ ). We then expressed the same MAP7 shRNA in rE17 DRG neuron (Fig. 3B). After $24 \mathrm{~h}$ in culture, the MAP7 shRNA caused a 25\% knockdown compared with the control shRNA, which is shown by the ratio of antibody labeling between endogenous MAP7 and neurofilament in the soma (Fig. $3 B, C$ ). We then analyzed branch morphology and found a $40 \%$ decrease in the total number of branches produced per MAP7-shRNA-transfected neuron compared with control shRNA transfections (Fig. $3 D-F$ ), as well as a $43 \%$ reduction compared with control EGFP-expressing neurons (Fig. $3 F$ ). The number of interstitial branches was also reduced significantly compared with the EGFP (43\%) and shRNA control (52\%) conditions, but the number of terminal branches did not change (Fig. $3 F$ ), suggesting that MAP7 is required for collateral branch formation. We also found a decrease (27-29\%) in axon length (Fig. $3 G$ ), but no significant difference in the number of axons from the cell body (Fig. $3 H$ ). Because the reduction in axonal length is less than the reduction in branch formation, these results support a role of MAP7 in collateral branch development in culture.

\section{MAP7 localizes to branch points along the axon}

To understand how MAP7 promotes branch formation, we inspected the localization of MAP7-EGFP overexpressed in rE14 DRG neurons and found that it accumulated at specific regions along the axon. Typically, expression of EGFP in neurons results in an even distribution of EGFP proteins throughout the neuron (Fig. $4 A-C$ ). Interestingly however, high levels of MAP7-EGFP were found in specific regions of the axons, usually associated with a branch (Fig. $4 D$, arrows). The concentrated signal was not due to the size difference of the axon because microtubules stained by $\alpha$-tubulin antibodies were distributed evenly along the axon (Fig. 4E,F). Closer inspection of MAP7 localization (Fig. $4 G-I$ ) showed a strong gradient that reached the highest level at the branch site (Fig. $4 F$, yellow box). Outside of this region, MAP7 has reduced signal in the portion of axons proximal to the soma (Fig. $4 D-F$, asterisks) and it rarely reaches to the growth cone. This increased MAP7 signal at the branch junctions places MAP7 at the precise location to influence DRG axon branching.

To confirm this localization, we examined endogenous MAP7 expression in cultured rE17 DRG neurons. We used a commercial antibody (GeneTex) raised against the C-terminal 147 aa residues to visualize MAP7 (Fig. $4 J$ ). When the signal was normalized to $\alpha$-tubulin staining (Fig. $4 K$ ), we found that endoge- 

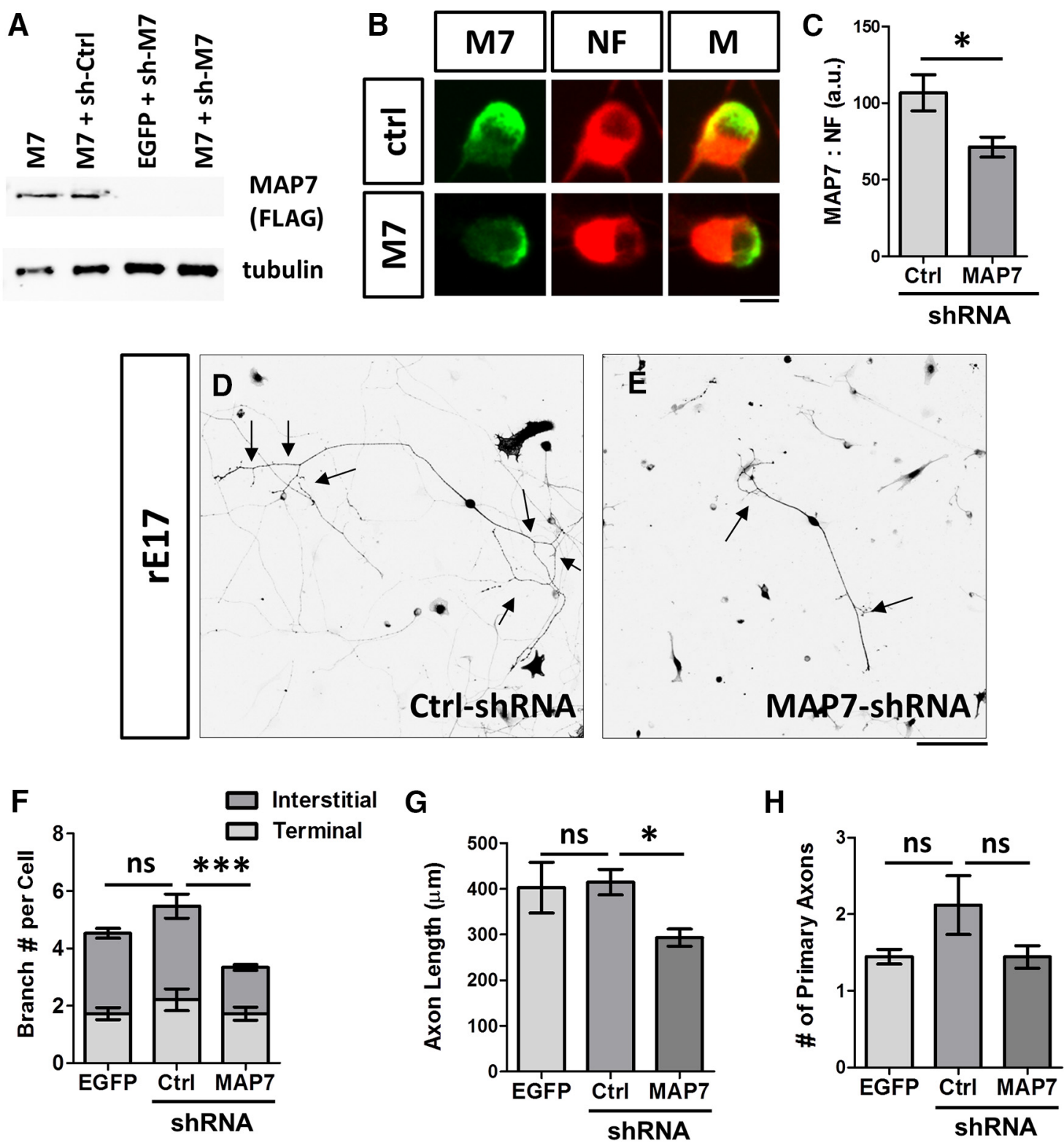

Figure 3. MAP7 knockdown decreases axon branching in cultured rat DRG neurons. A, Western analysis of COS cells expressing MAP7-FLAG(M7) and control shRNA (sh-Ctrl) or MAP7-specific (sh-M7) shRNA using antibodies against FLAG for MAP7 and tubulin for loading control. B, C, Analysis of shRNA knockdown of endogenous MAP7 in rE17 DRG neurons transfected with control (ctrl) or MAP7 (M7) shRNA. Confocal sections of the soma immunostained for MAP7 (M7; green, $\boldsymbol{B})$ and neurofilament (NF; red, $\boldsymbol{B})$ as well as the merged images $(\mathrm{M} ; \boldsymbol{B})$ are shown. Cells were selected based on mCherry expressed from the shRNA vector. The ratio in arbitrary units (a.u.) of fluorescence signals between MAP7 and NF is plotted for cells expressing control (Ctrl) or MAP7 shRNA (C). $n=41$ for Ctrl and 47 for MAP7. Scale bar, $5 \mu \mathrm{m} . \boldsymbol{D}, \boldsymbol{E}$, Inverted fluorescent images of rE17 DRG neurons expressing control (Ctrl, $\boldsymbol{D}$ ) or MAP7 (E) shRNA after grown overnight on laminin-coated coverslips and stained for mCherry expressed from the shRNA vector. Arrows point to interstitial branches. Scale bar, $100 \mu \mathrm{m}$. $\boldsymbol{F}-\boldsymbol{H}$, Quantification of the number (\#) of branches per cell in rE17 DRG neurons $(\boldsymbol{F})$ (total: EGFP: $5.8 \pm 0.3$; trl shRNA:5.5 $\pm 0.3 ;$ MAP7 shRNA:3.3 \pm 0.2; interstitial: EGFP: $2.8 \pm 0.2 ;$;trl shRNA:3.3 \pm 0.4; MAP7 shRNA: $1.6 \pm 0.1$; terminal: EGFP: $1.7 \pm 0.2 ;$ trrl shRNA:2.2 \pm 0.4; MAP7 shRNA: $1.7 \pm 0.1$.), length of main axons $(\boldsymbol{G})$, and number (\#) of primary axons $(\boldsymbol{H})\left(n=139\right.$ for EGFP, 45 for Ctrl shRNA, and 159 for MAP7 shRNA). ${ }^{*} p<0.05 ;{ }^{* * *} p<0.005 ; n s$, not significant from $t$ test for all comparisons except in C (Mann-Whitney test).

nous MAP7 was also present in concentrated regions along the axon and often present at branch points, consistent with the localization of overexpressed MAP7 in rE14 neurons (Fig. 4D-I).

To quantify the localization, we traced new branches back to their origins on the main axon and found that $50 \pm 15 \%$ of branches emerged from regions with high MAP7-EGFP expression in rE14 neurons and $72 \pm 9 \%$ of branches emerged from regions with endogenous MAP7 expression in rE17 neurons. Conversely, a branch emerged from MAP7-EGFP-rich regions $38 \pm 11 \%$ of times in rE14 neurons and $71 \pm 11 \%$ of times in rE17 neurons, indicating that MAP7 is present at the proper location to help regulate branch formation. These localization analyses suggest that MAP7 is in the right location to regulate axon branching.

\section{MAP7 promotes branch maturation}

To understand what role MAP7 plays at branch sites, we used time-lapse imaging to follow MAP7-EGFP-transfected rE14 DRG neurons over the course of new collateral branch formation. As shown in Figure 5A, MAP7-EGFP extended along the main axon, but did not reach the axonal terminals (asterisk). Between 0 and $10 \mathrm{~min}$, a new collateral branch (arrows) extended from a MAP7-EGFP-containing region, but no MAP7-EGFP was detected inside the nascent branch. Twenty minutes later, how- 


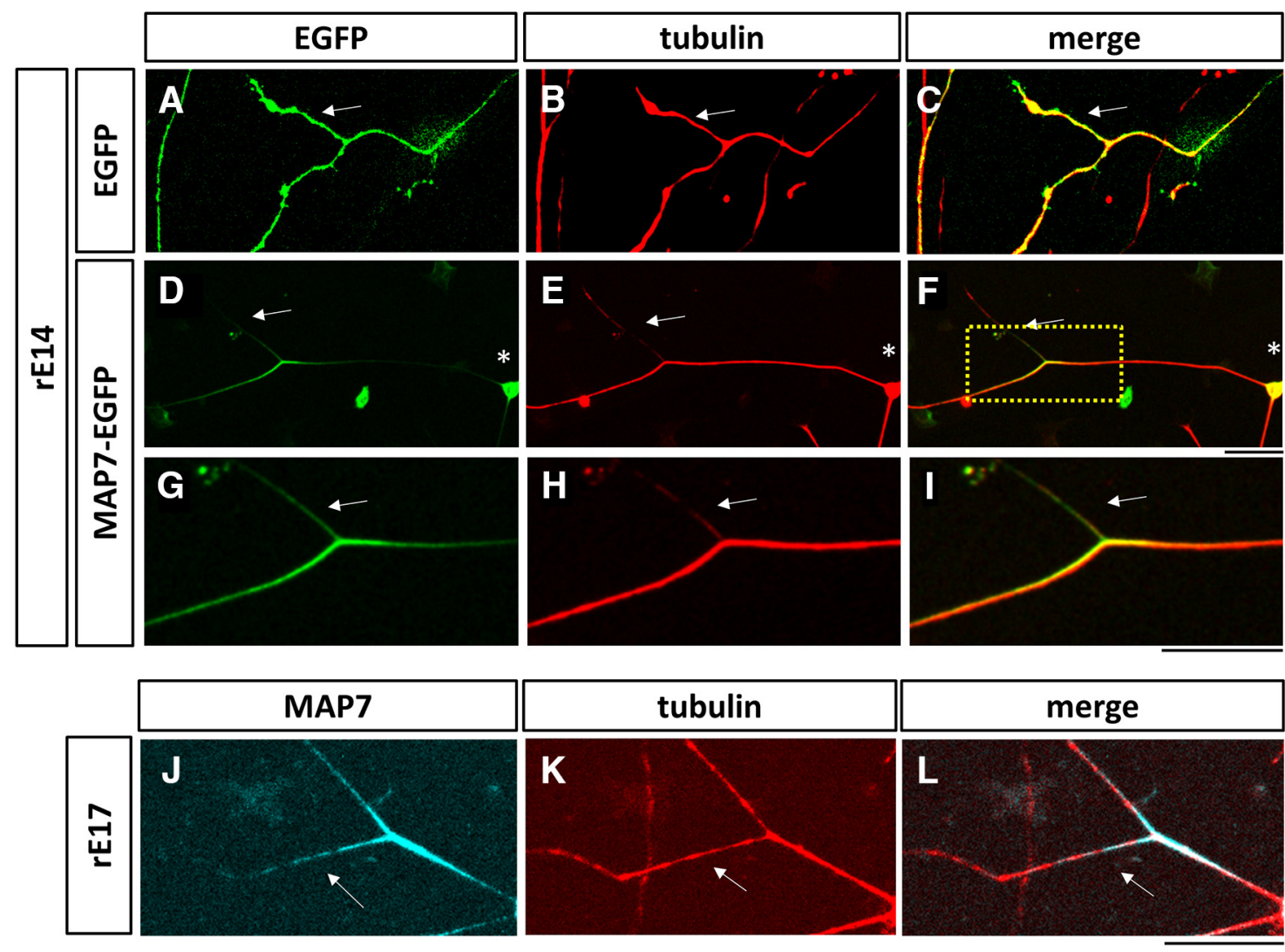

Figure 4. MAP7 is concentrated at branching sites. $A-I$, Dissociated rE14 DRG neurons expressing EGFP $(\boldsymbol{A}-\boldsymbol{C})$ or MAP7-EGFP $(\boldsymbol{D}-\boldsymbol{I})$ are shown by EGFP (green), antibody staining for $\alpha$-tubulin (red), or merged images. MAP7-EGFP can be seen entering into a new branch (arrow). Higher magnification image $(\mathbf{G}-\boldsymbol{I}$ ) of the branch site (yellow box in $\boldsymbol{F}$ ) shows the concentration of MAP7 at the branch site. $\boldsymbol{J}-\boldsymbol{L}$, rE17 DRG neurons were immunostained for endogenous MAP7 ( $\boldsymbol{J}$, cyan) and $\alpha$-tubulin ( $\boldsymbol{K}$, red). The merged image is shown in $\boldsymbol{L}$. MAP7 signal extends from the main axon into the branch (arrow). Scale bars, $20 \mu \mathrm{m}$.

ever, MAP7-EGFP started to enter the branch, but stayed behind the leading edge (arrows). In addition, more MAP7-EGFP accumulated at the base of the nascent branch, consistent with that found by staining (Fig. 4D-I). Therefore, MAP7 is needed inside of the newly formed branch and is likely to promote maturation via stabilizing the microtubules at branch sites and/or inside nascent branches.

To obtain further evidence to support this idea, we next examined filopodia formation, a process involved in branch initiation (Lewis et al., 2013; Kalil and Dent, 2014). We performed time-lapse imaging to monitor changes in filopodia dynamics in axonal regions containing EGFP or MAP7-EGFP (Fig. 5B). In control neurons, the EGFP signal was present in newly formed filopodia ( $2 \mathrm{~min}$ after appearance); in contrast, the MAP7-EGFP signal was absent from them, consistent with the lag seen above (Fig. 5A). Interestingly, however, formation of filopodia was not affected by MAP7-EGFP expression because neither the frequency of filopodia generated (Fig. 5C) nor the lifetime of filopodia (Fig. 5D) showed any significant difference between axonal regions expressing EGFP and MAP7-EGFP. These data suggest that the early stage of branch initiation is not affected by the presence of MAP7.

To gain evidence for a role of MAP7 in branch maturation, we next examined MAP7-EGFP in branches that had gone past the initiation phase of filopodium formation (Fig. 6A). Because branch maturation needs microtubules, we chose to analyze these branches positive with $\alpha$-tubulin staining (Fig. 6B). We also estimated the stages of branch development by dividing these branches into three length groups: (1) those shorter than $5 \mu \mathrm{m}$, likely being early or immature branches (Fig. 6A, $B$, arrowheads); 2) those between 5 and $20 \mu \mathrm{m}$, representing intermediate branches; and (3) those longer than $20 \mu \mathrm{m}$, likely being more mature branches (Fig. 6A, $B$, arrows). When the MAP7-EGFP signal was analyzed (Fig. 6A), we found it present in $100 \%$ of mature branches $(>20 \mu \mathrm{m})$ and in $50 \%$ of intermediate branches (Fig. 6D). However, MAP7 was rarely found in immature branches $(<5 \mu \mathrm{m})$ that contained microtubules (Fig. 6D). This result is again consistent with the delayed entry of MAP7 into newly formed branches and suggests a role of MAP7 during branch maturation.

To understand whether MAP7 affects microtubule stability during branch maturation, we next examined the distribution of stable microtubules using an antibody against acetylated tubulin (Garnham and Roll-Mecak, 2012) (Fig. 6C). We measured the fluorescent signal and compared the signal ratio of acetylated tubulin and $\alpha$-tubulin in the above three branch groups, which were further divided into MAP7 positive $(+)$ and negative $(-)$ subgroups (Fig. $6 E$ ). When MAP7 was present in branches, the ratio of acetylated tubulin and $\alpha$-tubulin was similar in all length groups, suggesting a good correlation between MAP7 and stable microtubules. Interestingly, the ratio was reduced by $40 \%$ in these immature branches $(<5 \mu \mathrm{m})$ that did not contain MAP7EGFP. The intermediate branches $(5-20 \mu \mathrm{m})$ showed a similar, albeit nonsignificant, reduction. This result, along with the strong association of MAP7 in mature branches, suggests that MAP7 can potentially increase the stable population of microtubules once it enters the nascent branch. 

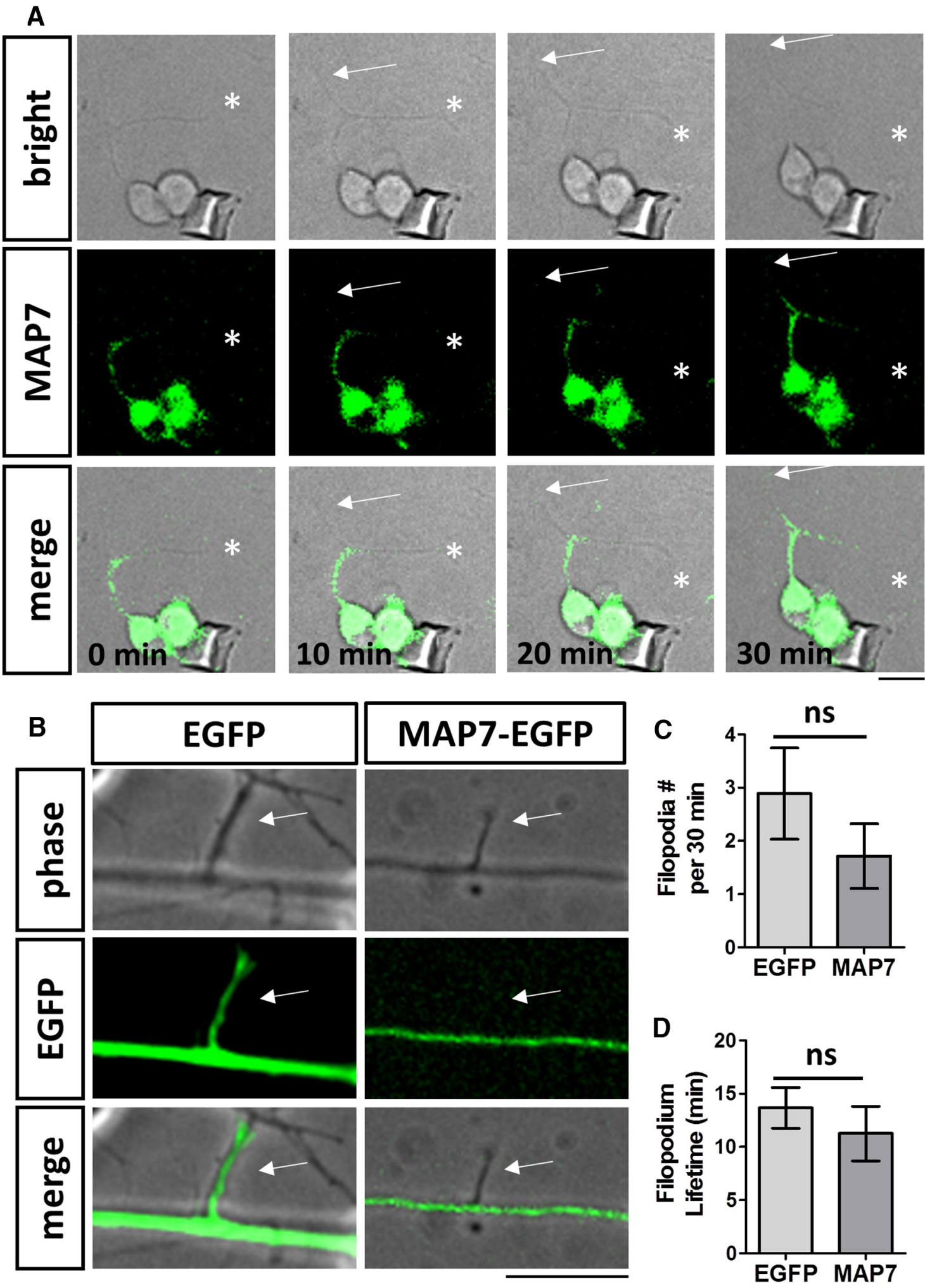

Figure 5. Time-lapse analysis reveals a delayed entry of MAP7 into new branches. A, Bright-field (top), MAP7-EGFP (middle), and merged (bottom) images of rE14 DRG neurons transfected with MAP7-EGFP are shown in a sequence with 10 min intervals. EGFP tagged proteins are present in the main axon but lag behind the terminals (asterisks). At 10 min, a new branch begins to form (arrows in phase), but does not contain MAP7-EGFP. At 20 min, MAP7-EGFP begins to enter the new branch, which continues to grow. MAP7-EGFP signal at the base of the branch is also increased. $n=4$. The middle two bright-field images were contrast enhanced in ImageJ. $\boldsymbol{B}$, Live-cell analysis of filopodium formation along transfected axons. Phase, EGFP, and merged images are shown for filopodia (arrows) formed in axonal regions expressing EGFP or MAP7-EGFP. The EGFP signal enters into the filopodia from the axonal region containing EGFP, but not MAP7-EGFP. C, D, Quantification of the number of filopodia formed every $30 \mathrm{~min}(\boldsymbol{C})$ and the total life time before they retract $(\boldsymbol{D})(n=27$ for EGFP and 13 for MAP7-EGFP). ns, not significant from $t$ test $(\boldsymbol{C})$ and Mann-Whitney test $(\boldsymbol{D})$. Scale bars, $10 \mu \mathrm{m}$. 

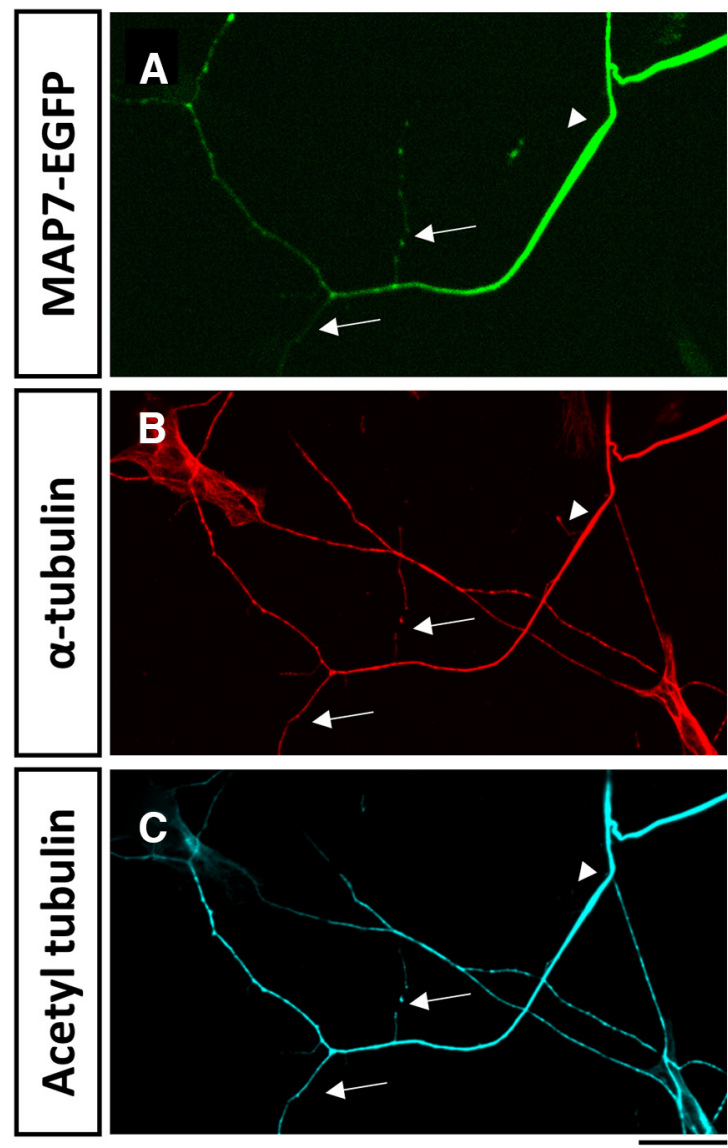

D

E
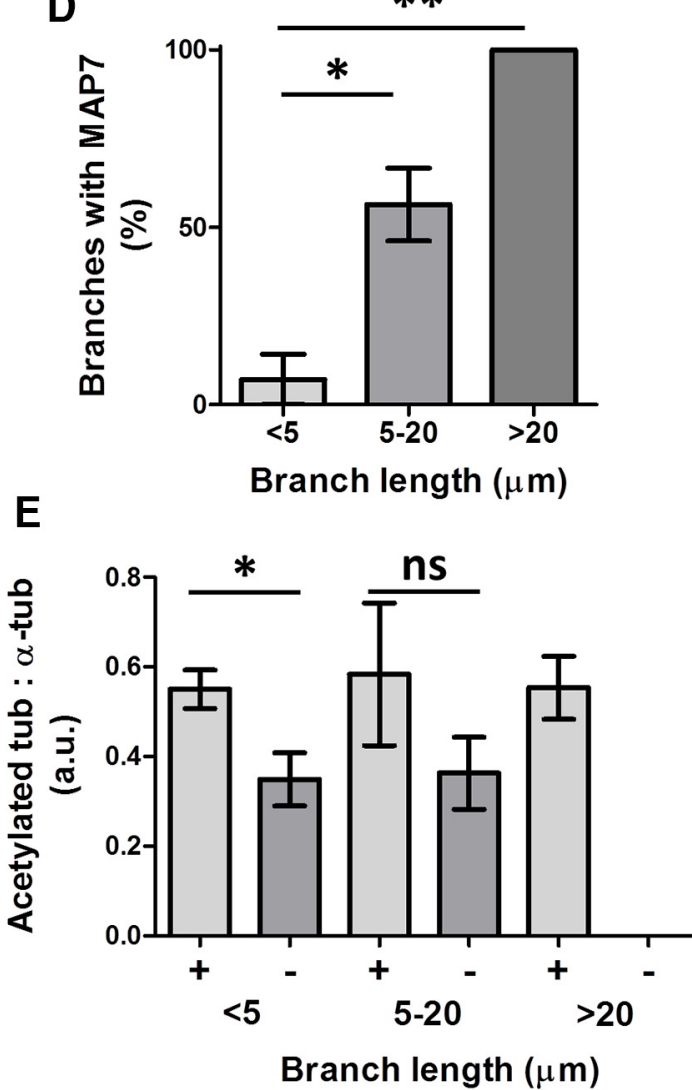

Figure 6. MAP7 localizes to longer and more stable branches and colocalize with acetylated microtubules. $\boldsymbol{A}$-C, A MAP7-EGFP-transfected rE14DRG neurons is shown for MAP7-EGFP fluorescence $(\boldsymbol{A}$, green) and antibody staining for $\alpha$-tubulin ( $\boldsymbol{B}$, red) or acetylated tubulin ( $\boldsymbol{C}$, cyan). MAP7-EGFP is only found in longer branches (arrows) but absent from branches shorter than $5 \mu \mathrm{m}$ (arrowheads). $\boldsymbol{D}, \boldsymbol{E}$, Quantification of the percentage of branches that contain MAP7 (D) and the fluorescent ratio in arbitrary units (a.u.) between acetylated tubulin (tub) and $\alpha$-tubulin $(\boldsymbol{E})$ in different branch length groups. Branches were divided into three groups based on length, $<5 \mu \mathrm{m}, 5-20 \mu \mathrm{m}$, and $>20 \mu \mathrm{m}$. Each group in $\boldsymbol{E}$ was further divided into a MAP7-positive ( + ) or MAP7-negative ( - ) subgroup. ${ }^{*} p<0.05,{ }^{* *} p<0.01 ;$ ns, not significant $(n=37$ branches) from Mann-Whitney test $(\boldsymbol{D})$ and $t$ test $(\boldsymbol{E})$. $p<0.0001$ from the Fisher's test for $\boldsymbol{D}$. Scale bar, $20 \mu \mathrm{m}$.

Increased branch formation of cultured DRG neurons from a spontaneous MAP7 mouse model

To demonstrate the physiological role of MAP7, we investigated a spontaneous mouse mutant (Map $7^{\mathrm{mshi}}$ ) that was originally identified by reduced sterility and loss of histocompatibility (Turner et al., 1997). Recent sequence analysis has found that the mutant has a $13 \mathrm{~kb}$ deletion in introns 10-11 (Magnan et al., 2009), resulting in the expression of a truncated protein (MAP7 ${ }^{\mathrm{mshi}}$ ) that has the C-terminal 315 aa residues replaced by 34 aa residues from the downstream cryptic exon (Fig. 7A, red box). To confirm the expression of the truncated MAP7 protein, we performed RNA in situ analysis in mE15.5 spinal cords using probes (Fig. $7 A$ ) against the $\mathrm{N}$ - or C-terminal region of MAP7. As shown in Figure $7 B$, the transcripts that could be recognized by the $\mathrm{N}$-terminal probe were present in the homozygous $M a p 7^{\text {mshi }}$ mutant, as well as in heterozygous and wild-type littermates. However, transcripts recognized by the C-terminal probes were only present in the wild-type or heterozygous DRGs, but not in the homozygous mutant DRGs. RT-PCR analysis confirmed this result (data not shown). Sequencing analysis of the RT-PCR product from the $M a p 7^{\text {mshi }}$ mutant confirmed that the transcript contained the predicted amino acid residues at the truncated junction (Fig. 7A).

Because MAP7 has been shown to interact with kinesin via its C-terminal domain (Fig. 7A) (Sung et al., 2008; Barlan et al., 2013), we reasoned that the endogenous expression of the
MAP7 ${ }^{\text {mshi }}$ truncation would block MAP7 function and thus branch formation. To test this hypothesis, we dissociated DRG neurons from these mice and examined axon branching in culture. Surprisingly, neurons from mE15.5 homozygous Map $7^{\text {mshi }}$ embryos showed a 2.4-fold increase in the number of branches per cell compared with wild-type neurons (Fig. 8A-C). This increase resulted from an increase in both interstitial branches (2.0fold) and terminal branches (3.1-fold). However, the primary axon number (Fig. $8 E$ ) and the average length of the main axons remained unchanged (Fig. $8 D$ ). Neurons from heterozygous animals also showed a small but significant increase (1.6-fold; Fig. $8 D$ ), indicating that the MAP7 truncation is a gain-of-function mutation with respect to branch formation in culture.

\section{Amino half of MAP7 is sufficient to promote}

branch formation

This unexpected gain-of-function phenotype suggests that the $\mathrm{N}$-terminal half of MAP7 is responsible for promoting collateral formation. MAP7 is composed of three subdomains (Fig. 7A): an $\mathrm{N}$-terminal microtubule-binding domain (CC1), a middle P domain containing $>34$ predicted phosphorylation sites (http:// www.cbs.dtu.dk/services/NetPhos/), and a coiled-coiled containing C-terminal domain (CC2) shown previously to interact with kinesin (Sung et al., 2008; Barlan et al., 2013). The result from the $M a p 7^{\text {mshi }}$ neurons suggests that the CC1 domain, but not the CC2 domain, is critical to branch formation. 


\section{A}
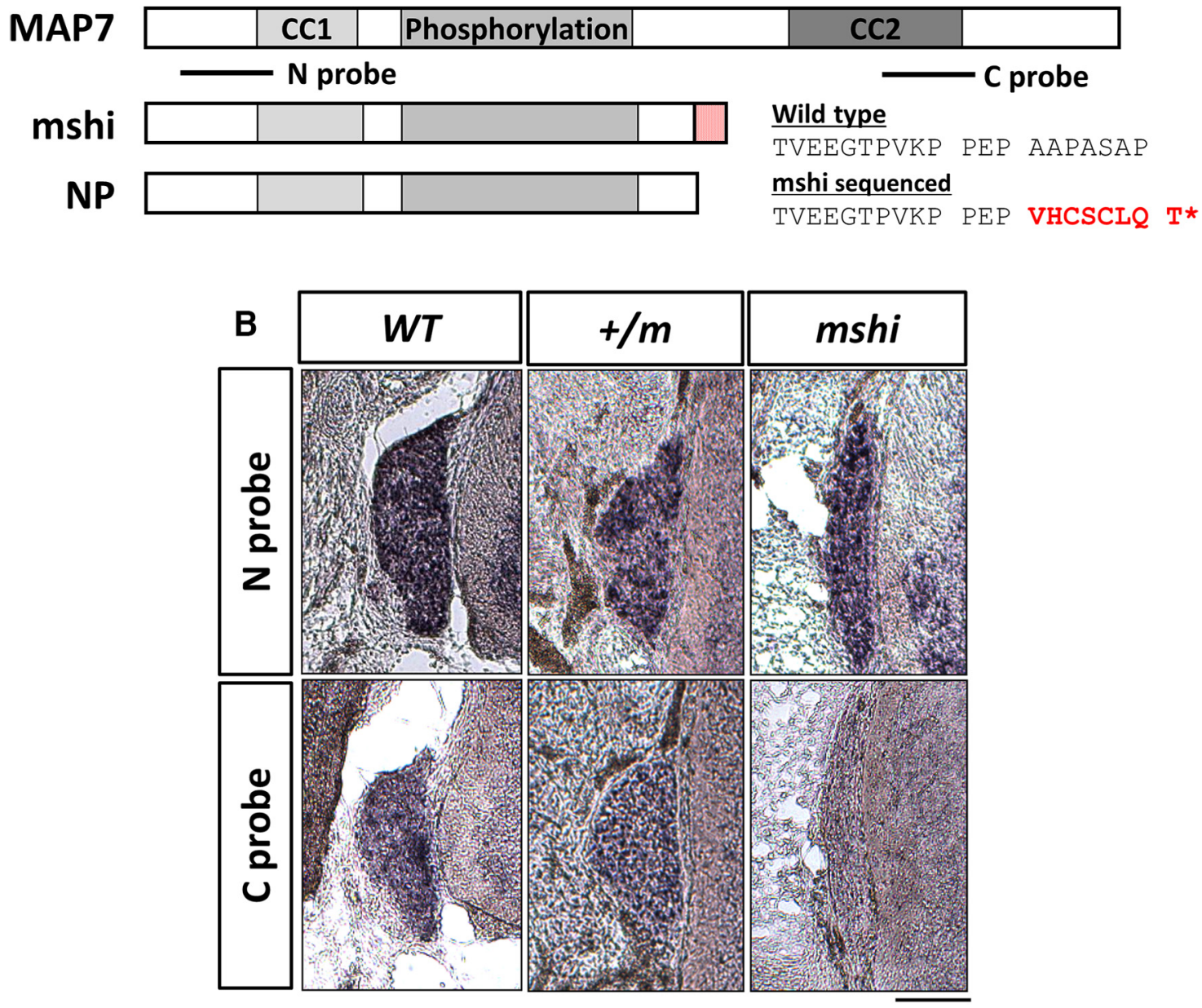

Figure 7. Analysis of MAP7 expression in the Map ${ }^{\text {mshi }}$ spinal cord. $A$, Schematic drawing of the primary structure of MAP7, the predicted truncation (mshi) generated in the Map $7^{\mathrm{mshi}}$ mouse, and the NP fragment used in the study. $C \mathrm{C} 1$ and $\mathrm{CC} 2$ denote the conserved region in MAP7 that bind to microtubules or kinesin, respectively. Amino acid sequences surrounding the truncation site are shown for wild-type and MAP7 ${ }^{\text {mshi }}$ (mshi) proteins. The sequence introduced by the cryptic exon insertion is shown in red. The locations of the two probes ( $\mathrm{N}$ - and $\mathrm{C}-$ ) used in the in situ analysis are also indicated. $\boldsymbol{B}$, In situ hybridization analysis of MAP7 expression in transverse sections of mE15.5 spinal cord from wild-type (WT), heterozygous ( $+/ \mathrm{m})$, and homozygous (mshi) Map mshi $^{\text {mb }}$ littermates using probes against the $\mathrm{N}$ - or C-terminal regions of the coding sequencing. Scale bar, $100 \mu \mathrm{m}$.

To further test this idea and to rule out the indirect effect from the additional sequence at the end of MAP7 ${ }^{\text {mshi }}$ truncation (Fig. $7 A$ ), we generated an amino fragment (NP) that contains the endogenous MAP7 sequence predicted to be in the MAP7 ${ }^{\text {mshi }}$ protein but lacks the sequence inserted from the cryptic exon (Fig. 7A). We overexpressed the EGFP fusion of the NP fragment in rE14 DRG neurons and tested whether it was sufficient to produce branches (Fig. $8 F, G$ ). Indeed, the NP fragment was able to promote axon branching, with an activity similar to MAP7 (Fig. 8H). NP-EGFP also had no significant effect on axon length or number of primary axons (Fig. $8 I, J$ ). Furthermore, the increase in branching was due to an increase in collateral branches rather than any change in terminal branching (Fig. $8 H$ ), suggesting that the NP region of MAP7 is responsible for promoting collateral branching in neurons. Inspection of the localization of NP-EGFP also revealed that the protein was restricted to the middle of the axon, with the highest level at the branch sites (Fig. $8 F, G$, arrows). These data indicate that the NP fragment of MAP7 is responsible for promoting branch formation and suggest that the kinesin interacting region is dispensable.
Increased collateral branching and pain sensitivity in $\operatorname{Map} 7^{\text {mshi }}$ mice

To gather further support of the gain-of-function phenotype and to demonstrate the in vivo role of MAP7 in axon branching, we performed single-cell DiI labeling of DRG axons in mouse embryos at E15.5, when collateral branches have just start to sprout from the main axons (Figs.9A, 9B, arrows) (Ozaki and Snider, 1997). In the wild-type spinal cord, $30 \pm 9 \%$ of DRG axons showed the presence of nascent collaterals, but in the homozygous $M a p 7^{\text {mshi }}$ spinal cord, $70 \pm 15 \%$ axons had at least one collateral branch, an increase of 2.3 -fold (Fig. 9 C). In the heterozygous animals, $48 \pm 10 \%$ axons had collaterals (Fig. 9C). This increase in $M a p 7^{\mathrm{mshi}}$ embryos is consistent with the behavior of $M a p 7^{\text {mshi }}$ neurons in culture and supports that the endogenously expressed MAP7 ${ }^{\mathrm{mshi}}$ truncation enhances the ability of axons to promote collateral branching in vivo.

We next investigated whether there were any functional consequences of increased collateral branching seen in $M a p 7^{\text {mshi }}$ mice embryos that may persist into adult mice. Because MAP7 is expressed in all DRG neurons, we chose to examine nociceptive response of 6-month-old male mice. We conducted Hargreaves 

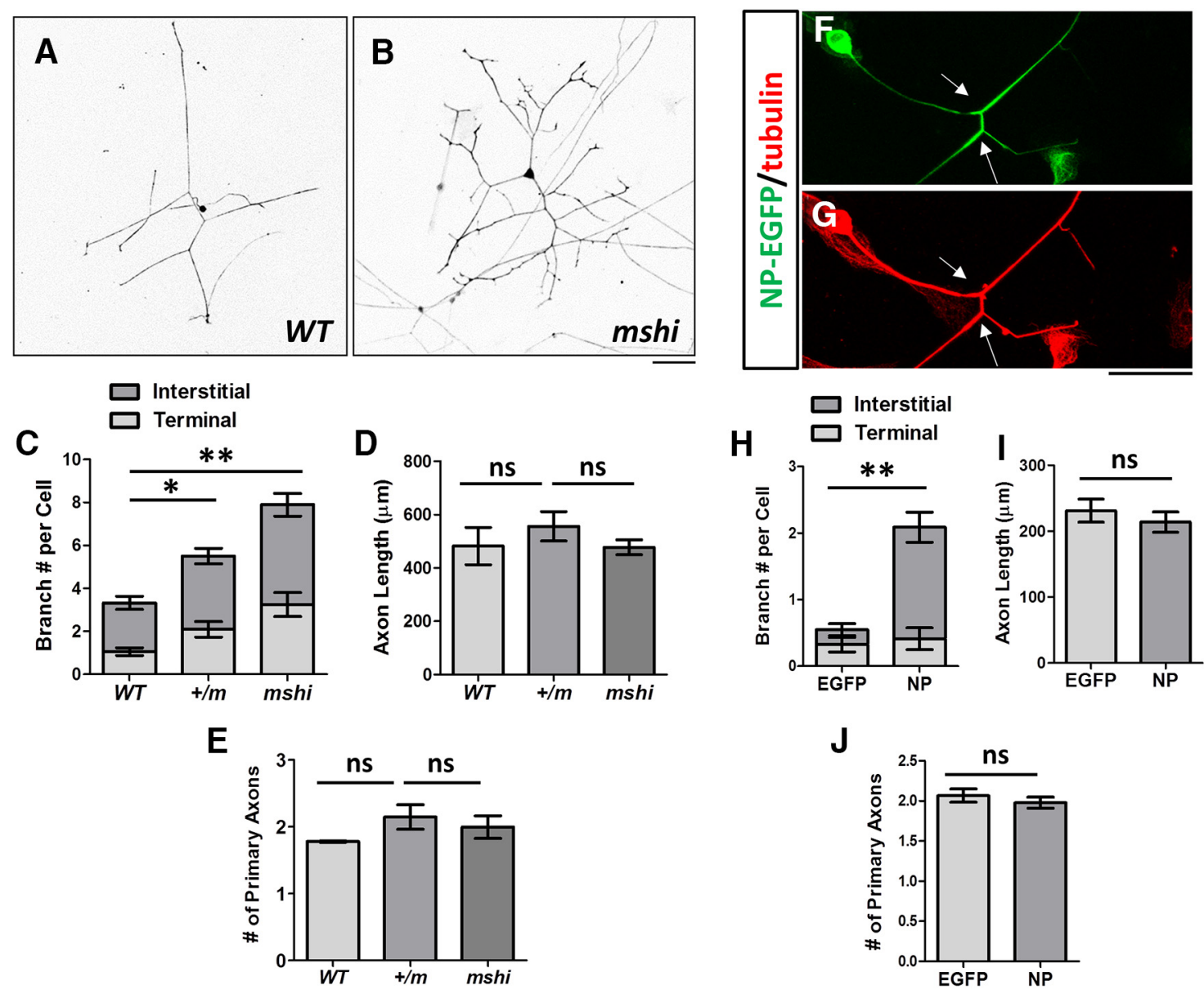

Figure 8. Increased branch formation in cultured Map $7^{\text {mshi }}$ neurons and rat DRG neurons expressing the NP fragment. $A, B$, Inverted fluorescent images of dissociated DRG neurons isolated from $\mathrm{mE15.5}$ wild-type $(W T, \boldsymbol{A})$ or Map $^{\mathrm{mshi}}(\mathrm{mshi}, \boldsymbol{B})$ littermates and cultured for $24 \mathrm{~h}$. Axons are visualized by immunostaining for neurofilament. $\boldsymbol{C}-\boldsymbol{E}$, Quantification of branch number (\#) per neurons $(\boldsymbol{C}$, main axon length (D), and primary axon number (\#) (E) for dissociated mE15.5 DRG neurons with different genotypes ( $n=93$ for all genotypes). Homozygous neurons ( $m$ shi) have $7.9 \pm 1.0$ total branches per cell, heterozygous neurons $(+/ m)$ have $5.5 \pm 0.6$, and wild-type $(W T)$ neurons have $3.3 \pm 0.4$. Interstitial branches per cell: $W T: 2.3 \pm 0.3 ;+/ m: 3.4 \pm 0.4 ; m s h i: 4.6 \pm 0.5$; and terminal branches per cell: WT: $1.1 \pm 0.2 ;+/ m: 2.1 \pm 0.4 ;$ mshi: $3.2 \pm 0.6$. F-G, rE14 DRG neurons cultured and transfected with NP-EGFP and visualized by EGFP $(\boldsymbol{F})$ or staining for $\alpha$-tubulin (G). $\boldsymbol{H}-\boldsymbol{J}$, Quantification of branches produced per neurons $(\boldsymbol{H})$, total axon length $(\boldsymbol{I})$, and number (\#) of primary axon $(\boldsymbol{J}) . n=52$ for EGFP and 23 for NP-EGFP. ${ }^{*} p<0.05$; ${ }^{* *} p<0.01$; ns, not significant from $t$ test for all except $J$ (Mann-Whitney test). Scale bars, $20 \mu \mathrm{m}$.

heat testing, a behavioral paradigm in which the latency of forepaw withdrawal is measured in response to application of a noxious thermal stimulus. Interestingly, homozygous $M A P 7^{\mathrm{mshi}}$ animals showed a faster withdrawal response to the heat stimulus (left paw, $11.5 \pm 1.7 \mathrm{~s}$; right paw, $11.0 \pm 1.5 \mathrm{~s}$ ) compared with heterozygous littermates (left paw, $24.1 \pm 1.4 \mathrm{~s}$; right paw, $21.5 \pm$ $1.1 \mathrm{~s}$ ) (Fig. 9D). Although MAP7 is not expressed in motor neurons, we wanted to rule out any potential effect on forelimb motor function. Using forelimb grip strength testing, we found no differences between the littermates (Fig. 9E), confirming that the enhanced nociceptive response was not due to changes in motor function. We also analyzed the peripheral nerves using neurofilament antibodies and found no observable defect in the forelimb (Fig. 9G,H). Because the animals expressing the MAP7 ${ }^{\text {mshi }}$ truncation have increased embryonic collateral branching and adult hypersensitivity to heat-induced pain, our results thus suggest a potential functional consequence of having increased DRG collateral branching.

\section{Discussion}

Although much of our current understanding of collateral branch development centers on extracellular signaling, cytoskeletal assembly, and transcriptional regulation (Gallo, 2011; Gib- son and Ma, 2011; Bilimoria and Bonni, 2013; Lewis et al., 2013; Kalil and Dent, 2014), little is known about how these mechanisms are used for developmental control of collateral branch formation. DRG sensory axons provide a good model with which to investigate this question because they contain an intrinsic switch critical to their collateral branch development. The fact that old (E15.5 in mouse and E17 in rat) but not young (E12.5 in mouse and E14 in rat) neurons retain the ability to make branches in culture indicates the presence of molecular changes responsible for regulating collateral branching (Wang et al., 1999; Gibson and Ma, 2011; Kalil and Dent, 2014). Based on expression profiling and functional studies, our study has identified MAP7 as one of the major molecular players in this developmental switch. Furthermore, our analysis of a spontaneous mouse mutant supports this notion and further provides mechanistic insights into the cell biological mechanism of branch regulation.

\section{Novel role of MAP7 in developmental regulation of DRG axon branching}

Previous studies of MAP7 have focused on its effects in mammalian cell lines or Drosophila cells (Masson and Kreis, 1993; Bulinski and Bossler, 1994; Bulinski et al., 2001; Gruber et al., 2001; Sung et al., 2008; Magnan et al., 2009; Metzger et al., 2012; Barlan 

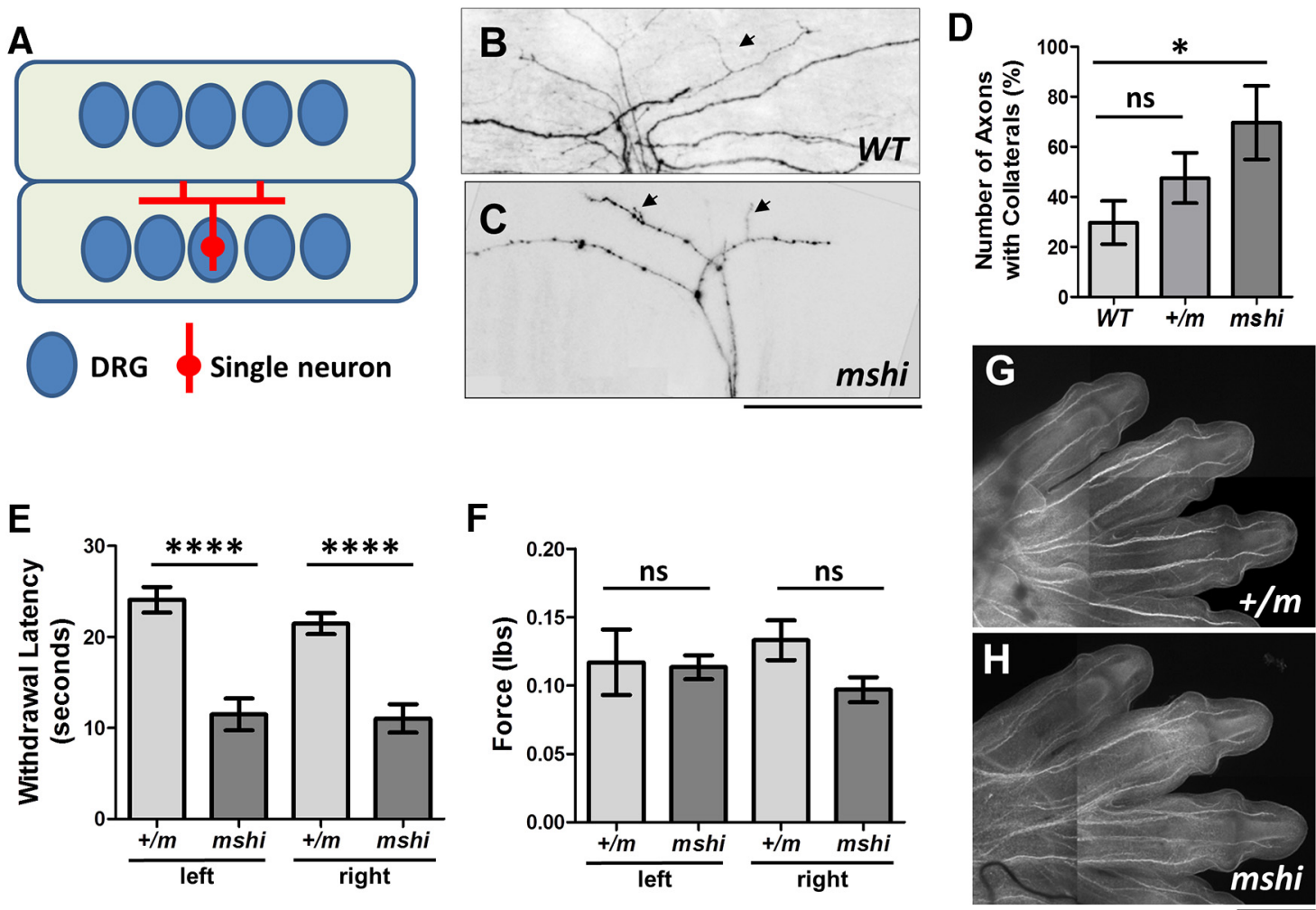

Figure 9. Map $7^{\mathrm{mshi}}$ mice have increased collateral branches and pain sensitivity. $\boldsymbol{A}-\boldsymbol{C}$, Schematic $(\boldsymbol{A})$ and examples of Dil-labeled single DRG axons in E15.5 spinal cord of wild-type (WT, $\left.\boldsymbol{B}\right)$ and $M_{A P 7}{ }^{\text {mshi }}(m s h i, C)$ mice. Arrows point to the newly formed collaterals. $\boldsymbol{D}$, Comparison of the number of axons displaying at least one collateral branch from Dil labeling of DRG neurons from wild-type (WT), heterozygous $(+/ m)$, or homozygous ( $m$ shi) animals $\left(n=32\right.$ for $W T, 50$ for $+/ m$, and 29 for mshi). ${ }^{*} p<0.05$, Mann-Whitney test. $p<0.0001$ from the Fisher's test. $E$, $F$, Analysis of forepaw withdrawal response time to a nociceptive thermal stimulus by 6-month-old heterozygous $(+/ m)$ and homozygous mutant $(m s h i)$ male mice $(\boldsymbol{E})$ and assessment of forelimb motor functions using grip strength testing on the same animals $(\boldsymbol{F})$ from left or right side of the body $\left(n=4\right.$ animals per condition). ${ }^{*} p<0.05 ;{ }^{* * * *} p<0.0001 ; n$, not significant from $t$ test. $\mathbf{G}, \boldsymbol{H}$, Neurofilament labeling of peripheral nerves in E15.5 forelimbs of heterozygous $(+/ m, \boldsymbol{G})$ and homozygous mutant $(m s h i, \boldsymbol{H})$ animals. Scale bars, $50 \mu \mathrm{m}$.

et al., 2013; Gallaud et al., 2014; Yadav et al., 2014), but very little is known about its function in the nervous system, despite its wide expression in neurons (Fabre-Jonca et al., 1998; Komada et al., 2000). Our in situ data in mouse tissues (Fig. 1) showed that MAP7 expression switches on in a subpopulation of DRG cells at $\mathrm{mE} 13.5$, the same time when collateral projections begin to invade the spinal cord. The large increase found at $\mathrm{mE15.5}$, precisely at the time of collateral branch formation, supports the role of MAP7 in establishing new branches (Fig. 1). Furthermore, perturbation studies by precocious expression in rE14 neurons and shRNA knockdown in rE17 neurons demonstrate the branchpromoting functions of MAP7 (Figs. 2, 3). This activity is further supported by the analysis of the Map $7^{\text {mshi }}$ mouse, which has increased branching in culture and increased collateral branch formation in vivo (Figs. 8, 9). Therefore, our study has identified a major role of MAP7 in the developmental regulation of collateral branch formation of DRG sensory axons. Because MAP7 has been associated recently with autism and schizophrenia (Torri et al., 2010; Venkatasubramanian, 2015; Rouillard et al., 2016), one can imagine that it influences branch morphogenesis of other neuronal cell types that are critical to these neurological disorders. Therefore, it would be interesting to further analyze MAP7 function in other parts of the nervous system.

Previous study of cytoskeletal regulation in branch formation has mainly focused on local events, especially at the sites of branching. Our results now demonstrate that precise regulation of gene expression of a cytoskeletal regulator can also influence the progress of branch development. Although other factors might still be needed in development, switching on MAP7 at the onset of DRG collateral branch formation endows DRG neurons with the ability to form collateral branches. This developmental expression echoes previous studies of tau and other MAPs during axonal growth. For example, embryonic and adult neurons express different ratios of tau isoforms, whereas MAP1A and MAP1B act in a complementary way to each other (Tucker, 1990). Tau and MAP1B are switched on early during development to perform specific roles such as axon polarization and axon outgrowth and are then downregulated at older ages (Tucker, 1990; Rösner et al., 1995). Our study of MAP7 not only provides a new example of such regulation, but also demonstrates the precise nature of this regulation: transcriptional activation at a specific time during axonal morphogenesis. Several transcriptional regulators have been identified in our microarray analysis (data not shown) and further characterization of these factors and their relationship with MAP7 will help in our understanding of the detailed mechanism for this global regulation during development.

\section{MAP7 regulates branch maturation by microtubule binding} and stabilization

What is the exact function of MAP7 during collateral branch formation? Our study reveals that MAP7 accumulates at the sites on main axons where new branches tend to form (Fig. 4). We also observed that there was a delay between the branch emergence and the appearance of MAP7 within the branch (Fig. 5A). These two pieces of data suggest a role for MAP7 in promoting branch maturation rather than initiation. Further support comes from the study of these two distinct events, branch initiation mediated 
by filopodium formation and branch maturation mediated by microtubules. First, MAP7 does not alter branch initiation: neither the frequency of filopodium formation nor the lifetime or duration of filopodia was altered in the presence of MAP7 (Fig. $5 C, D)$. Second, MAP7 is absent from short, presumably immature branches $(<5 \mu \mathrm{m})$, but appears in longer and more mature branches (5-20 $\mu \mathrm{m}$ and $>20 \mu \mathrm{m}$ ) (Fig. 6). Furthermore, the presence of MAP7 in the branches correlates with the increase of acetylated tubulin, a sign for increased microtubule stability.

Based on these cell biological analyses, we propose that MAP7 stabilizes microtubules to promote branch maturation during collateral development. This function fits well with the current understanding of microtubule behavior and collateral branch development (Lewis et al., 2013; Kalil and Dent, 2014). As shown by an early study of DRG axons (Gallo and Letourneau, 1999), microtubules are often transported into newly formed branches. Once in the nascent branches, these so-called "floating" microtubules need to be stabilized to enable the branch to grow. Here, we found that MAP7 follows microtubules into nascent branches and is associated with stable microtubules. Therefore, MAP7 serves as an excellent candidate for stabilizing these newly arrived microtubules in branches and preventing them from sliding back into the axon.

This notion is also supported by our studies of the spontaneous Map $7^{\text {mshi }}$ mouse and the NP fragment (Fig. 7), which suggest that MAP7 likely influences microtubule stability via its $\mathrm{N}$-terminal microtubule-binding domain. This domain of MAP7 is highly conserved throughout vertebrates (81-89\%) and shows homology with the invertebrate Drosophila homolog ensconsin (61\%), but shares no sequence homology to microtubule-binding domains found in other MAPs. Because of its unique sequence, it would be interesting to understand the mechanism underlying this regulation. In addition, our results also suggest that stabilizing microtubules alone is not sufficient to promote branching. For example, the microtubule-stabilizing drug Taxol promotes only axon elongation but not branching (Gallo and Letourneau, 1999; Ertürk et al., 2007; Witte et al., 2008), and we show here that MAP7 promotes branching but not axon elongation. Such a difference suggests a unique MAP7 regulatory mechanism that warrants further investigation.

Furthermore, although MAP7 has been shown to promote kinesin-1 activity (Sung et al., 2008), our study suggests that its direct interaction with kinesin is dispensable for branch formation (Figs. 8, 9). Because MAP7 is also expressed in other parts of the brain (Fabre-Jonca et al., 1998; Komada et al., 2000), it would be interesting to test whether it acts in a similar manner to regulate collateral branching in other neuronal cell types. Regardless, our studies open the door to further investigation of the precise mechanism of microtubule regulation by MAP7 during branch morphogenesis.

\section{Potential role of collateral branch regulation and circuit functions}

The function of collateral branches is to increase the network connectivity of individual neurons. Our studies provide new insights into the importance of the role of collateral branch development in establishing functional neural circuits within the spinal cord. The Map $7^{\text {mshi }}$ mouse model has increased collateral branch formation, leading to an increase in reflex response to thermal nociception (Fig. 9). The nociception reflex circuits consist of both peripheral and central axons of DRG neurons, the interneurons, and the motor neurons. Because MAP7 is only expressed in the DRG neurons and there is no observable defect in motor function (Fig. 9E) or peripheral branching (Fig. 9G,H) of the Map $7^{\mathrm{mshi}}$ mouse, it is intriguing to suggest that the increased sensitivity results from the overproduction of collateral branches. However, because the overbranching phenotype was found in embryos and the nociception defect was observed in adult animals, further analysis of adult branching at the singlecell level is needed before drawing a firm conclusion. In addition, it would be interesting to investigate whether collateral branches for other sensory modalities are also affected and if there are increased functional synapses with their targets. Finally, physiological analysis of the reflex circuits will be useful to determine the effect of increased collateral on synaptic functions.

Nevertheless, the functional change described here suggests that the excess branches found in early development may persist into adulthood. Although further analysis is needed, such a result would support a role of MAP7 in branch stabilization and maintenance. Finally, the identification of this dominant-active region of MAP7 has implications for therapeutic uses because manipulation of MAP7 in injured DRG circuits could prove beneficial for axon regeneration (Ertürk et al., 2007; Baas, 2014). Although further work is needed to establish the precise regulatory mechanisms of MAP7, our studies have demonstrated the importance of MAP7 in axonal development both in vitro and in vivo.

\section{References}

Arber S, Ladle DR, Lin JH, Frank E, Jessell TM (2000) ETS gene Er81 controls the formation of functional connections between group Ia sensory afferents and motor neurons. Cell 101:485-498. CrossRef Medline

Baas PW (2014) Beyond taxol: microtubule-based strategies for promoting nerve regeneration after injury. Neural Regen Res 9:1265-1266. CrossRef Medline

Barlan K, Lu W, Gelfand VI (2013) The microtubule-binding protein ensconsin is an essential cofactor of kinesin-1. Curr Biol 23:317-322. CrossRef Medline

Bilimoria PM, Bonni A (2013) Molecular control of axon branching. Neuroscientist 19:16-24. CrossRef Medline

Bouquet C, Soares S, von Boxberg Y, Ravaille-Veron M, Propst F, Nothias F (2004) Microtubule-associated protein 1B controls directionality of growth cone migration and axonal branching in regeneration of adult dorsal root ganglia neurons. J Neurosci 24:7204-7213. CrossRef Medline

Bulinski JC, Bossler A (1994) Purification and characterization of ensconsin, a novel microtubule stabilizing protein. J Cell Sci 107:2839-2849. Medline

Bulinski JC, Gruber D, Faire K, Prasad P, Chang W (1999) GFP chimeras of E-MAP-115 (ensconsin) domains mimic behavior of the endogenous protein in vitro and in vivo. Cell Struct Funct 24:313-320. CrossRef Medline

Bulinski JC, Odde DJ, Howell BJ, Salmon TD, Waterman-Storer CM (2001) Rapid dynamics of the microtubule binding of ensconsin in vivo. J Cell Sci 114:3885-3897. Medline

Cajal Ry (1995) Histology of the nervous system. Oxford: OUP.

Dent EW, Kalil K (2001) Axon branching requires interactions between dynamic microtubules and actin filaments. J Neurosci 21:9757-9769. Medline

Ertürk A, Hellal F, Enes J, Bradke F (2007) Disorganized microtubules underlie the formation of retraction bulbs and the failure of axonal regeneration. J Neurosci 27:9169-9180. CrossRef Medline

Fabre-Jonca N, Allaman JM, Radlgruber G, Meda P, Kiss JZ, French LE, Masson D (1998) The distribution of murine 115-kDa epithelial microtubuleassociated protein (E-MAP-115) during embryogenesis and in adult organs suggests a role in epithelial polarization and differentiation. Differentiation 63:169-180. CrossRef Medline

Faire K, Waterman-Storer CM, Gruber D, Masson D, Salmon ED, Bulinski JC (1999) E-MAP-115 (ensconsin) associates dynamically with microtubules in vivo and is not a physiological modulator of microtubule dynamics. J Cell Sci 112:4243-4255. Medline

Falnikar A, Hala TJ, Poulsen DJ, Lepore AC (2016) GLT1 overexpression reverses established neuropathic pain-related behavior and attenuates 
chronic dorsal horn neuron activation following cervical spinal cord injury. Glia 64:396-406. CrossRef Medline

Gallaud E, Caous R, Pascal A, Bazile F, Gagné JP, Huet S, Poirier GG, Chrétien D, Richard-Parpaillon L, Giet R (2014) Ensconsin/Map7 promotes microtubule growth and centrosome separation in Drosophila neural stem cells. J Cell Biol 204:1111-1121. CrossRef Medline

Gallo G (2011) The cytoskeletal and signaling mechanisms of axon collateral branching. Dev Neurobiol 71:201-220. CrossRef Medline

Gallo G, Letourneau PC (1999) Different contributions of microtubule dynamics and transport to the growth of axons and collateral sprouts. J Neurosci 19:3860-3873. Medline

Garnham CP, Roll-Mecak A (2012) The chemical complexity of cellular microtubules: tubulin post-translational modification enzymes and their roles in tuning microtubule functions. Cytoskeleton 69:442-463. CrossRef Medline

Gibson DA, Ma L (2011) Developmental regulation of axon branching in the vertebrate nervous system. Development 138:183-195. CrossRef Medline

Gruber D, Faire K, Bulinski JC (2001) Abundant expression of the microtubule-associated protein, ensconsin (E-MAP-115), alters the cellular response to Taxol. Cell Motil Cytoskeleton 49:115-129. CrossRef Medline

Hargreaves K, Dubner R, Brown F, Flores C, Joris J (1988) A new and sensitive method for measuring thermal nociception in cutaneous hyperalgesia. Pain 32:77-88. CrossRef Medline

Homma N, Takei Y, Tanaka Y, Nakata T, Terada S, Kikkawa M, Noda Y, Hirokawa N (2003) Kinesin superfamily protein 2A (KIF2A) functions in suppression of collateral branch extension. Cell 114:229-239. CrossRef Medline

Kalil K, Dent EW (2014) Branch management: mechanisms of axon branching in the developing vertebrate CNS. Nat Rev Neurosci 15:7-18. CrossRef Medline

Kapitein LC, Hoogenraad CC (2015) Building the neuronal microtubule cytoskeleton. Neuron 87:492-506. CrossRef Medline

Ketschek A, Jones S, Spillane M, Korobova F, Svitkina T, Gallo G (2015) Nerve growth factor promotes reorganization of the axonal microtubule array at sites of axon collateral branching. Dev Neurobiol 75:1441-1461. CrossRef Medline

Komada M, McLean DJ, Griswold MD, Russell LD, Soriano P (2000) E-MAP-115, encoding a microtubule-associated protein, is a retinoic acid-inducible gene required for spermatogenesis. Genes Dev 14:13321342. Medline

Lewis TL Jr, Courchet J, Polleux F (2013) Cell biology in neuroscience: cellular and molecular mechanisms underlying axon formation, growth, and branching. J Cell Biol 202:837-848. CrossRef Medline

Ma L, Tessier-Lavigne M (2007) Dual branch-promoting and branchrepelling actions of Slit/Robo signaling on peripheral and central branches of developing sensory axons. J Neurosci 27:6843-6851. CrossRef Medline

Magnan DR, Spacek DV, Ye N, Lu YC, King TR (2009) The male sterility and histoincompatibility (mshi) mutation in mice is a natural variant of microtubule-associated protein 7 (Mtap7). Mol Genet Metab 97:155162. CrossRef Medline

Masson D, Kreis TE (1993) Identification and molecular characterization of E-MAP-115, a novel microtubule-associated protein predominantly expressed in epithelial cells. J Cell Biol 123:357-371. CrossRef Medline

Metzger T, Gache V, Xu M, Cadot B, Folker ES, Richardson BE, Gomes ER, Baylies MK (2012) MAP and kinesin-dependent nuclear positioning is required for skeletal muscle function. Nature 484:120-124. CrossRef Medline

Mirnics K, Koerber HR (1995) Prenatal development of rat primary afferent fibers: II. Central projections. J Comp Neurol 355:601-614. CrossRef Medline

Moffat J, Grueneberg DA, Yang X, Kim SY, Kloepfer AM, Hinkle G, Piqani B, Eisenhaure TM, Luo B, Grenier JK, Carpenter AE, Foo SY, Stewart SA, Stockwell BR, Hacohen N, Hahn WC, Lander ES, Sabatini DM, Root DE (2006) A lentiviral RNAi library for human and mouse genes applied to an arrayed viral high-content screen. Cell 124:1283-1298. CrossRef Medline
Ozaki S, Snider WD (1997) Initial trajectories of sensory axons toward laminar targets in the developing mouse spinal cord. J Comp Neurol 380:215229. Medline

Patel TD, Kramer I, Kucera J, Niederkofler V, Jessell TM, Arber S, Snider WD (2003) Peripheral NT3 signaling is required for ETS protein expression and central patterning of proprioceptive sensory afferents. Neuron 38: 403-416. CrossRef Medline

Qiang L, Yu W, Andreadis A, Luo M, Baas PW (2006) Tau protects microtubules in the axon from severing by katanin. J Neurosci 26:3120-3129. CrossRef Medline

Qiang L, Yu W, Liu M, Solowska JM, Baas PW (2010) Basic fibroblast growth factor elicits formation of interstitial axonal branches via enhanced severing of microtubules. Mol Biol Cell 21:334-344. CrossRef Medline

Rösner H, Rebhan M, Vacun G, Vanmechelen E (1995) Developmental expression of tau proteins in the chicken and rat brain: rapid downregulation of a paired helical filament epitope in the rat cerebral cortex coincides with the transition from immature to adult tau isoforms. Int $J$ Dev Neurosci 13:607-617. CrossRef Medline

Rouillard AD, Gundersen GW, Fernandez NF, Wang Z, Monteiro CD, McDermott MG, Ma'ayan A (2016) The harmonizome: a collection of processed datasets gathered to serve and mine knowledge about genes and proteins. Database (Oxford) 2016.

Sung HH, Telley IA, Papadaki P, Ephrussi A, Surrey T, Rørth P (2008) Drosophila ensconsin promotes productive recruitment of Kinesin-1 to microtubules. Dev Cell 15:866-876. CrossRef Medline

Susaki EA, Tainaka K, Perrin D, Kishino F, Tawara T, Watanabe TM, Yokoyama C, Onoe H, Eguchi M, Yamaguchi S, Abe T, Kiyonari H, Shimizu Y, Miyawaki A, Yokota H, Ueda HR (2014) Whole-brain imaging with single-cell resolution using chemical cocktails and computational analysis. Cell 157:726-739. CrossRef Medline

Torri F et al. (2010) Fine mapping of AHI1 as a schizophrenia susceptibility gene: from association to evolutionary evidence. FASEB J 24:3066-3082. CrossRef Medline

Tucker RP (1990) The roles of microtubule-associated proteins in brain morphogenesis: a review. Brain Res Brain Res Rev 15:101-120. CrossRef Medline

Turner JP, Carpentino JE, Cantwell AM, Hildebrandt AL, Myrie KA, King TR (1997) Molecular genetic mapping of the mouse male sterility and histoincompatibility (mshi) mutation on proximal chromosome 10. Genomics 39:1-7. CrossRef Medline

Tymanskyj SR, Scales TM, Gordon-Weeks PR (2012) MAP1B enhances microtubule assembly rates and axon extension rates in developing neurons. Mol Cell Neurosci 49:110-119. CrossRef Medline

Venkatasubramanian G (2015) Understanding schizophrenia as a disorder of consciousness: biological correlates and translational implications from quantum theory perspectives. Clin Psychopharmacol Neurosci 13: 36-47. CrossRef Medline

Wang KH, Brose K, Arnott D, Kidd T, Goodman CS, Henzel W, TessierLavigne M (1999) Biochemical purification of a mammalian slit protein as a positive regulator of sensory axon elongation and branching. Cell 96:771-784. CrossRef Medline

Winkle CC, Taylor KL, Dent EW, Gallo G, Greif KF, Gupton SL (2016) Beyond the cytoskeleton: the emerging role of organelles and membrane remodeling in the regulation of axon collateral branches. Dev Neurobiol 76:1293-1307. CrossRef Medline

Witte H, Neukirchen D, Bradke F (2008) Microtubule stabilization specifies initial neuronal polarization. J Cell Biol 180:619-632. CrossRef Medline

Yadav S, Verma PJ, Panda D (2014) C-terminal region of MAP7 domain containing protein 3 (MAP7D3) promotes microtubule polymerization by binding at the C-terminal tail of tubulin. PLoS One 9:e99539. CrossRef Medline

Zhao Z, Wang Z, Gu Y, Feil R, Hofmann F, Ma L (2009) Regulate axon branching by the cyclic GMP pathway via inhibition of glycogen synthase kinase 3 in dorsal root ganglion sensory neurons. J Neurosci 29:13501360. CrossRef Medline 